
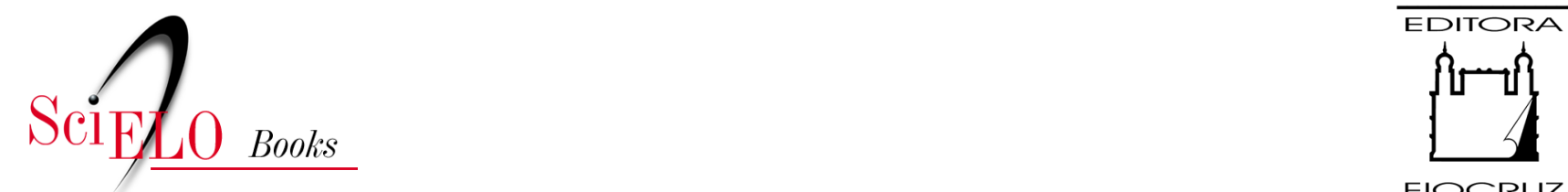

FIOCRUZ

\title{
5. Arquitetura e saúde no Rio de Janeiro
}

\author{
Renato da Gama-Rosa Costa
}

\section{SciELO Books / SciELO Livros / SciELO Libros}

COSTA, R.G.R. Arquitetura e saúde no Rio de Janeiro. In: PORTO, Â., SANGLARD, G., FONSECA, M.R.F., and COSTA, R.G.R., orgs. História da saúde no Rio de Janeiro: instituições e patrimônio arquitetônico (1808-1958) [online]. Rio de Janeiro: Editora FIOCRUZ, 2008, pp. 117-142. ISBN: 978-85-7541-599-3. Available from: doi: 10.7476/9788575415993.0007. Also available in ePUB from: http://books.scielo.org/id/7f83x/epub/porto-9788575415993.epub.

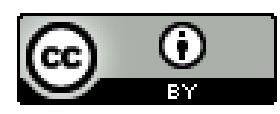

All the contents of this work, except where otherwise noted, is licensed under a Creative Commons Attribution $\underline{4.0 \text { International license. }}$

Todo o conteúdo deste trabalho, exceto quando houver ressalva, é publicado sob a licença Creative Commons Atribição 4.0. 
5

\section{Arquitetura e Saúde no Rio de Janeiro}

Renato da Gama-Rosa Costa 


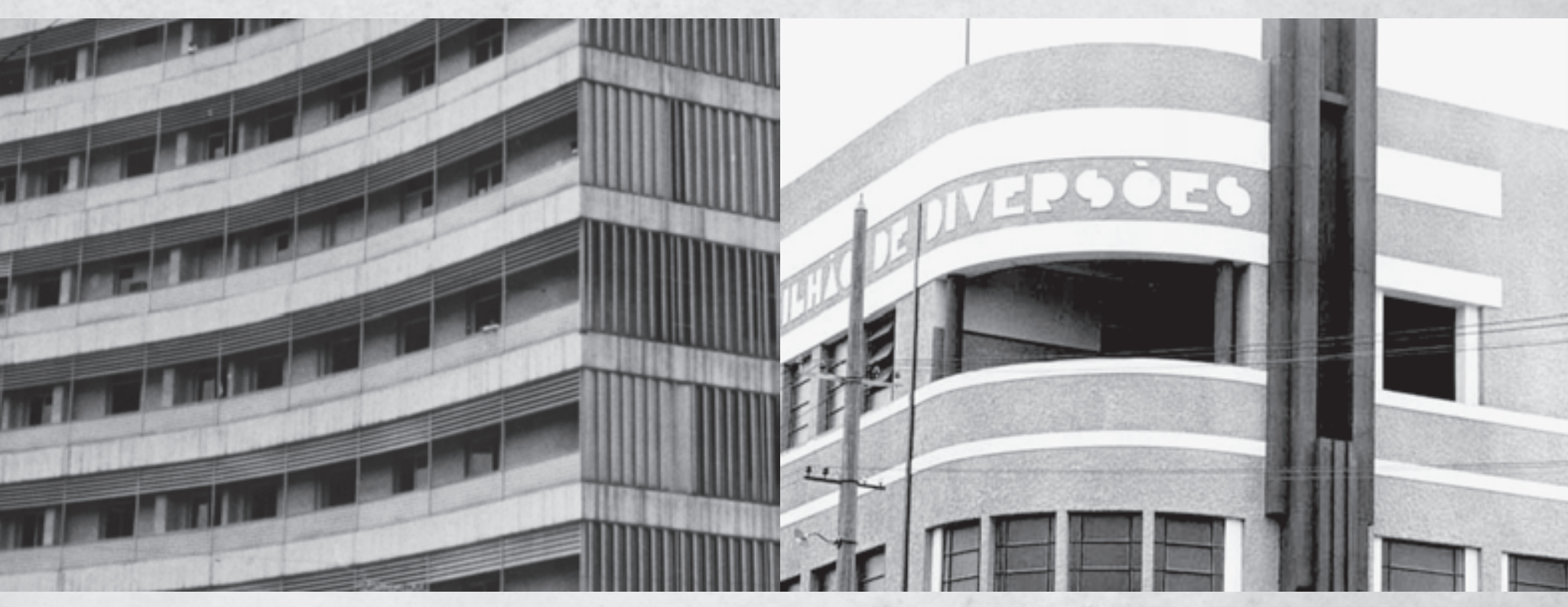


A história do hospital como instituição conta com alguns estudos clássicos desenvolvidos, mas a investigação em arquitetura hospitalar se apresenta ainda fértil. No Brasil, à exceção de estudos pioneiros de Miquelin (1992), Bittencourt (2000) e, mais recentemente, de Toledo (2006), ainda se busca quem se proponha a contar a história da arquitetura hospitalar por meio de estudos de caso. Esse é um dos objetivos deste livro e deste capítulo, em particular.

Segundo Foucault (1999), o hospital como instrumento de cura é invenção recente do final do século XVIII. Isso porque, segundo ele, o hospital não era lugar da prática médica, e o médico não fazia do hospital lócus de atuação ou de aprimoramento de seus estudos terapêuticos. O hospital era território de religiosos e suas irmandades, que visavam a amparar os pobres até sua morte. A reconstrução do HôtelDieu de Paris, entre 1772 e 1788, depois de um incêndio, iria deflagar uma tomada de consciência sobre o estado deplorável das condições higiênicas dos antigos hospitais de caridade. O tradicional uso do hospital para diferentes fins e atendimento a doentes acometidos das mais variadas formas de infecção junto com os feridos, as parturientes e as crianças, aliado a uma nova concepção de ventilação e aeração dos quartos, fez com que se criticasse a usual planta em quadrado ou em cruz dos hospitais antigos, passando-se a adotar a forma do hospital em pavilhões.

Para a reconstrução do hospital, foi convocado o cirurgião francês Jacques Tenon, que juntamente com o inglês Horward e o austríaco Hunczovsky realizavam, desde 1760, estudos comparativos buscando demonstrar estatisticamente a relação entre a taxa de mortalidade, certas práticas médicas e os espaços internos dos hospitais, tendo como inspiração o Hospital Stonehouse, de Plymouth, projetado naquele ano pelo engenheiro Roverhead (Mignot, 1983). Tal hospital seria, então, o modelo utilizado como referência para a reconstrução do hospital parisiense e de outros hospitais franceses, e foi aprovado pela Academia de Ciências daquele país, em 1786. A comissão formada por Tenon, Howard e Hunczovsky propunha, em resumo, o número de 1.200 leitos para os hospitais; maior isolamento; disposição e abertura nos quartos visando à melhor renovação do ar; organização dos pavilhões de isolamento de forma mais ordenada, dispostos em paralelo e orientados mais favoravelmente no sentido norte-sul, e, em sua maioria, compostos de um a dois pavimentos, com raras concessões a três pisos.

Entretanto, tal modelo não seria aplicado plenamente antes de 1830-1850, na construção do Hospício da Renascença, em Garches, ou mesmo antes de 1874, na construção do Hospital Lariboisière. Em certa medida, a subseqüente nacionalização das propriedades clericais na França teria contribuído para esse 
atraso (Mignot, 1983). Ao longo da segunda metade do século XIX, os hospitais comandados pelas igrejas dariam lugar a hospitais organizados por médicos, e a arquitetura dos espaços de saúde passaria a ser entendida como instrumento de cura tanto quanto "um regime alimentar, uma sangria e um gesto médico" (Foucault, 1999: 109).

Para que assim ocorresse, foi decisiva a promulgação da lei republicana francesa de 15 de julho de 1893, que instituía a assistência médica gratuita. Essa lei possibilitava que as comunas financiassem a internação de cidadãos privados de recursos e obrigava os hospitais a atendê-los. Dessa forma, os poderes públicos passaram a exigir que as admissões de doentes fossem feitas por médicos, tirando das freiras essa prerrogativa. Assim, o hospital passaria a ser gradualmente comandado por médicos, atendendo todo tipo de citadinos, fossem eles doentes venéreos ou mulheres parturientes. Essas mudanças trariam alterações profundas na arquitetura hospitalar (Faure, 1994), e esta nunca mais seria a mesma.

Pretendemos analisar aqui como tais mudanças foram traduzidas nas construções hospitalares na cidade do Rio de Janeiro, percebendo semelhanças e especificidades, e examinando as escolhas de linguagem e de forma, abrangendo desde o Hospital da Santa Casa até os hospitais monoblocos. Ou seja, da arquitetura que atendia às necessidades do culto religioso à arquitetura que seguia os preceitos higiênicos, ou da arquitetura de challet à arquitetura funcionalista.

Outro aspecto que abordaremos está relacionado à gradual atuação dos arquitetos, que assumiram a função de principais articuladores do projeto de um hospital a partir da segunda metade do século XX, com o advento da denominada arquitetura moderna. Esta utilizaria tal tipo de programa como forma de exercitar ao máximo sua capacidade de articulação de usos complexos e conhecimentos científicos em uma construção civil (Anelli, Guerra \& Nelson, 2001). Segundo o arquiteto paulista Rino Levi (1945), autor de sete projetos hospitalares realizados entre 1945 e 1960 no Brasil e na América Latina, ${ }^{1}$ a elaboração de um projeto hospitalar depende de uma equipe multidisciplinar composta por médicos e especialistas de diversas áreas, sendo o arquiteto o coordenador capaz de reunir as contribuições de cada um dos profissionais envolvidos (Anelli, Guerra \& Nelson, 2001).

Entretanto, tal metodologia de construção de hospitais teria outros resultados. As décadas de $1960 \mathrm{e}$ 1970 assistiriam a uma predominância da técnica sobre a arquitetura no uso da tipologia do monobloco, construção que reunia em uma só edificação os setores destinados ao tratamento de doenças diferentes, antes separados por pavilhões. Em busca de uma funcionalidade extrema, o que se percebe é que, a partir de então, a tecnologia da construção seria cada vez mais predominante, em detrimento de uma maior capacidade criativa dos arquitetos. Não por acaso, resolvemos delimitar nossa pesquisa até o ano de 1958, anterior a essas duas décadas.

A evolução da arquitetura para a saúde não apresenta uma linearidade, que possa dar a entender que uma solução posterior seria melhor que a anterior; nessa trajetória percebem-se a co-existência, em determinadas épocas, de dois ou mais modelos. Na verdade, o que se percebe é que essa disciplina procurou responder da melhor maneira possível aos desafios impostos na sua relação interdependente, ao longo de séculos, com a medicina, que também, por sua vez, não seguiu de forma linear e progressiva. 


\section{A Assistência aos Pobres e o Hospital Religioso}

Roberto Machado (Machado et al., 1978) e Russel-Wood (1981) foram dos poucos estudiosos a realizar investigação mais profunda sobre os hospitais das casas da Misericórdia, trazendo o tema para a especificidade brasileira. Segundo Russel-Wood, em toda a América espanhola a responsabilidade pelos serviços hospitalares não cabia à municipalidade. A Igreja e as ordens religiosas assumiam tal tarefa, que no Brasil caberia à Irmandade da Misericórdia, a mais ativa nesse aspecto, mesmo que de forma limitada.

O primeiro Hospital da Santa Casa do Rio de Janeiro, de 1582, era parte de um conjunto de obras de caridade oferecidas pelas misericórdias, divididas em sete espirituais e sete corporais. Ao hospital cabia, certamente, curar os enfermos; cobrir os nus; dar de comer aos famintos; dar de beber a quem tem sede; dar pousada aos peregrinos e pobres; enterrar os mortos. Para Machado, "o serviço hospitalar da Santa Casa do Rio de Janeiro limitava-se, no começo do século XVIII, a apenas dois médicos, um cirurgião e um enfermeiro auxiliado por um ajudante e mais dois escravos, para uma população de mais ou menos duzentos e cinqüenta doentes" (Machado et al., 1978: 59).

A instalação da Corte portuguesa, em 1808, no Rio de Janeiro traria mudanças significativas nessa relação. Em 1813, determinou-se que a Academia Médico-Cirúrgica tivesse seu curso ministrado no Hospital da Santa Casa. Tal situação se manteria mesmo depois da criação da Faculdade de Medicina do Rio de Janeiro, em 1832. A convivência com a faculdade foi fundamental para que o estabelecimento da Misericórdia fosse palco das transformações no exercício das artes de curar e não apenas de amparar a morte. A presença da medicina acadêmica naquele ambiente e o aumento do número de atendidos tornaram evidentes os problemas da estrutura física do prédio, considerado inapropriado para o tratamento dos enfermos, segundo as concepções médicas da época. Além do mais, as discussões na Assembléia Constituinte de 1823, questionando os espaços da Santa Casa, considerados insalubres, levaram à elaboração de um relatório que recomendava a construção de um novo hospital para a Santa Casa; este foi edificado em 1854, já dentro dos preceitos da higiene, como veremos adiante. Tal relatório indicava, ainda, outros melhoramentos na área da saúde, como a construção de edifícios especiais para os alienados, para os expostos e para as órfãs.

No Hospital dos Lázaros, a maior atenção à arquitetura revela o grau da cumplicidade estabelecida em certo momento entre arquitetura, medicina e religião. O hospital foi construído entre 1748 e 1752 , constituindo-se de uma planta quadrangular, com pátios internos e capela central, disposição que se manteve mesmo depois da adaptação para receber os leprosos, em 1766. As celas dos jesuítas, usadas como quartos para os pacientes, assim permaneceram até 1892, quando foram finalmente destruídas, transformando-se o espaço em salões-enfermarias (Pôrto \& Oliveira, 1996). Era rara a presença de médico, sendo os pacientes atendidos por cirurgião e auxiliados por enfermeiros e pelos religiosos.

Procurando acompanhar os avanços no tratamento e conforto dos pacientes e atender aos preceitos da higiene, o lazareto passou por diversas reformas, principalmente no último quartel do século XIX. As reformas continuaram no século seguinte, entre 1917 e 1920, e permitiram que suas instalações se tornassem modelo de higiene, incentivando outras melhorias, precursoras do que seria exigido para as construções hospitalares nos anos posteriores. Em termos formais, o Hospital dos Lázaros procurou manter as linhas mais próximas às da arquitetura religiosa, adotando o neogótico como elemento principal de linguagem 
e estilo. Ao longo das reformas, as construções do lazareto incorporaram elementos estéticos neoclássicos, ecléticos e art nouveau, sem entretanto deixar de lado a referência religiosa.

Os projetos arquitetônicos de espaços de isolamento para alienados, como o asilo de mendicidade construído entre 1884 e 1889, desenvolveram-se em composições que seguiam os princípios de instituições prisionais da Europa, como o panóptico de Bentham. O partido arquitetônico ${ }^{2}$ do asilo, atual Hospital São Francisco, adotou a configuração volumétrica formada por um corpo central e cinco bastões em justaposição, em dois pavimentos. Essa solução radial, que induzia ao confinamento e ao controle, também foi objeto de projetos para hospitais que encontram no Brasil pouquíssimos exemplares, sendo um dos mais destacados o do Sanatório de Belém, localizado em área afastada da cidade de Porto Alegre. Na reforma que transformou o antigo asilo em hospital-geral, a estrutura original de alas foi aproveitada como hospital pavilhonar - adaptação para salões-enfermarias, criação de consultório isolado, racionalização do sistema de higiene e de circulação. ${ }^{3}$ Fazia parte do projeto original uma capela localizada no corpo central da edificação, evidenciando o quanto, tradicionalmente, se devia à religião o tratamento de seus doentes.

\section{Da Arquitetura Higienista à Arquitetura dos Pavilhões}

A higiene seria responsável pela transformação na forma arquitetônica dos primeiros hospitais, principalmente depois das epidemias que assolaram o Rio de Janeiro na segunda metade do século XIX. Tais preceitos foram traduzidos em investimentos na separação de alas para enfermos, independentes porém interligadas por corredores muitas vezes subterrâneos; no isolamento das grandes concentrações urbanas; na atenção aos benefícios da aeração e ao combate à umidade.

O novo hospital para a Santa Casa de Misericórdia obedeceu a tais princípios, erguendo, entre 1840 e 1852, uma grande construção com feições neoclássicas, distribuída em dez alas e seis pátios internos, de composição simétrica e quadrangular, projetada pelo arquiteto-engenheiro José Domingos Monteiro, ex-integrante do Imperial Corpo de Engenheiros e arquiteto da Câmara. Monteiro foi designado como arquiteto das obras da Santa Casa pelo provedor da instituição, José Clemente Pereira, que fez um levantamento dos defeitos das antigas instalações, então em desacordo com as regras de higiene do Oitocentos: arquitetura irregular; enfermarias situadas abaixo do solo, úmidas e destituídas da necessária circulação de ar; enfermarias muito pequenas para as mulheres; os tísicos, assim como os bexiguentos, não separados dos demais doentes; acomodações para os alienados que pareciam cárceres. Tais condições eram agravadas por infiltrações, goteiras e ameaças de desabamento em algumas partes do edifício.

Um relato de viagem produzido à época (1868-1870) pela expedição de Bourdel-Roncière, médico francês responsável pela saúde a bordo de uma das embarcações francesas que respondia aos interesses da geografia médica e da colonização européia (Morais, 2007), atestava a situação desfavorável da Santa Casa do ponto de vista da higiene. Relatos como esse legitimavam a autoridade dos médicos europeus e seu diagnóstico sobre um país, essencial para o andamento da empresa colonialista:

Suas opiniões sobre as condições gerais dos hospitais, as doenças mais comuns, o número de funcionários disponíveis - médicos, farmacêuticos e enfermeiros -, as despesas hospitalares, a arquitetura do prédio 
e os tratamentos correntemente utilizados pelas comunidades médicas locais serviam como verdadeiros guias às autoridades governamentais e, conseqüentemente, a outros médicos exploradores. (Morais, 2007: 47 $)^{4}$

Segundo o relato, a arquitetura do prédio da Santa Casa foi considerada à altura dos melhores estabelecimentos europeus, principalmente os franceses, tidos como modelos. Foram elogiados, igualmente, o bom espaço entre as camas, o tamanho dos corredores e a existência de jardins, elementos essenciais para a salubridade de um hospital. Apesar dos elogios também quanto aos materiais empregados em sua construção - granitos e madeiras nobres -, revelando o esforço empreendido por Monteiro e Pereira, a higiene hospitalar deixava muito a desejar. Sua localização aos pés do morro do Castelo era tida como inapropriada do ponto de vista higiênico, "em virtude da quase perpendicularidade dos morros em relação aos ventos, o que representava um obstáculo à ventilação" (Morais, 2007: 49). Sabemos o quanto a localização de um hospital era importante para a manutenção de suas condições salubres.

De fato, nesse mesmo período deu-se a construção do Hospício Pedro II. Seguindo os preceitos de proporcionar "calma, tranqüilidade e espaço" aos alienados (Tundis \& Costa, 1990: 38), a edificação do hospício foi implantada na praia Vermelha, um sítio afastado da cidade e muito arejado. O acesso difícil tornava garantido o isolamento dos pacientes, bem como a proteção contra eventuais fugas. O partido adotado para o hospício de isolamento foi o de forma pavilhonar, com seis pátios internos. Sua configuração obedeceu a um programa comum aos estabelecimentos hospitalares de Paris, confirmando o Hôtel-Dieu como grande modelo a servir de inspiração em todo o mundo; seu programa constituía-se de enfermarias, farmácia, salões e uma capela.

Até o final do século XIX seriam construídos o Hospital da Beneficência Portuguesa, o Hospital São Sebastião e o Hospital Evangélico. O que se percebe de comum às arquiteturas desses hospitais é a tentativa de responder com qualidade construtiva às questões impostas pela higiene: o uso de pavilhões de isolamento para o acolhimento das doenças infectocontagiosas ou separação por sexo; o uso de pátios internos e grandes janelas para facilitar a aeração e a ventilação dos quartos. E no caso do São Sebastião, adotou-se ainda o isolamento da malha urbana.

Quanto à linguagem arquitetônica, vê-se o uso do neoclássico, conjugado com o estilo challet na decoração e no uso dos materiais construtivos. De forma geral, o neoclássico aparece nos edifícios principais do conjunto, com destaque para as fachadas de acesso, tendo a linguagem do challet se restringido ao interior das edificações ou aos pavilhões de isolamento. No caso da Beneficência Portuguesa, seu edifício principal, construído entre 1848 e 1853, apresenta o único exemplar de frontão arqueado do classicismo carioca, elemento que seria repetido no pavilhão construído quarenta anos depois.

As opções pela linguagem neoclássica e em challet permaneceriam ainda em alguns hospitais na primeira década do século XX, embora já inseridos na releitura proporcionada pelo movimento do ecletismo arquitetônico, como no Hospital da Cruz Vermelha, no Hospital de Manguinhos e naquele construído para o Instituto Nacional de Educação de Surdos. Foi uma época de novas descobertas da medicina, como a da transmissão de doenças por germes, e o trabalho do engenheiro francês Casimir Tollet, de 1892, apresentou uma solução definitiva para a renovação do ar nas enfermarias que consistia na construção de ambientes com paredes de altura elevada, com seção em arco e abertura no teto, junto aos telhados, de modo a permitir a saída do ar viciado pela parte de cima do ambiente. Tal sistema 
permitiria um novo tipo de inserção do hospital no meio urbano, sem as exigências de espaços ao redor da edificação para a ventilação e renovação do ar ao nível das janelas.

O projeto do Hospital de Manguinhos, de Luiz Moraes Jr., construído durante os últimos anos de vida de Oswaldo Cruz, entre 1912 e 1917, ainda seguia as recomendações de um hospital higiênico: amplas varandas, pé-direito alto e sistema de refrigeração, que facilitavam a aeração e proporcionavam maior conforto nos quartos. O programa norteador, no entanto, foi a bacteriologia, segundo a qual cada doença deveria ser combatida em separado, ou seja, em cada pavilhão. Seu projeto original previa a construção de mais cinco outros pavilhões. Tal empreendimento não logrou êxito, dada a morte prematura do cientista, e o único pavilhão construído destinou-se ao tratamento de doenças tropicais, como a doença de Chagas, a febre amarela, a leishmaniose visceral e tegumentar, a doença de Lutz e o pênfigo foliáceo.

As descobertas feitas especialmente por Pasteur e seus seguidores e a progressiva individualização das doenças infectocontagiosas, associando um micróbio a uma enfermidade e seus sintomas, levariam a uma revisão da terapia do isolamento. Para as doenças que ainda exigiam o afastamento do paciente do restante da sociedade, o hospital de isolamento ainda era o modelo a se seguir. Em termos de arquitetura, os sanatórios experimentariam uma série de referências e formas construtivas, tornando-se laboratórios de pesquisa estética e construtiva.

Para atender aos demais tratamentos que não necessitavam de isolamento e para outras enfermidades que surgiriam com a modernidade do século XX que já se anunciava, como os ferimentos de guerra e os decorrentes de acidentes do trabalho e do trânsito, seriam construídos os hospitais gerais e de prontosocorro. Estes passaram a ocupar terrenos urbanos mais centrais.

Em certa medida, isso foi sentido na criação dos hospitais da Cruz Vermelha, que visavam a atender aos feridos dos inúmeros episódios de conflitos no século XIX, estimulando o trabalho, desde 1863, do Comitê Internacional para Ajuda aos Militares Feridos. Em 5 de dezembro de 1908, foi fundada a Cruz Vermelha Brasileira, como órgão de assistência pública e privada no Rio de Janeiro, com o intuito de estabelecer no país um corpo de auxílio hospitalar semelhante aos criados em outras cidades do mundo, localizados em pleno centro urbano. De certa forma, a inauguração do Hospital de Pronto-Socorro (atual Hospital Municipal Souza Aguiar), em 1925, visava a atender aos acidentados, vindo a se localizar em plena praça da República.

\section{Os Anos 20 e a Arquitetura de Transição, entre o Modelo Higienista, o Pavilhonar e o Monobloco}

A década de 1920, no Rio de Janeiro, foi um período de busca de novos tratamentos e terapias, situados entre a tradição das Misericórdias e a modernidade trazida pelos estudos da bacteriologia, que se impunha cada vez mais. A produção para a saúde nesses anos esteve concentrada nos projetos hospitalares do engenheiro-geógrafo Adelstano Porto d'Ave, a serviço da reforma sanitária empreendida por Carlos Chagas, à frente do Departamento Nacional de Saúde Pública, e das ações filantrópicas da família Guinle. À semelhança do que ocorrera com o arquiteto Luiz Moraes, que acompanhara Oswaldo Cruz em sua gestão na então Diretoria-Geral de Saúde Pública e no Instituto Oswaldo Cruz, realizando, a pedido do cientista, os projetos de construções entre os quais se incluía um bom número de edificações 
hospitalares, o grau de parentesco com os Guinle permitiu que Porto d'Ave desenvolvesse os projetos de três hospitais planejados por Carlos Chagas. ${ }^{5}$

Foram projetados, então, o Hospital Gaffrée \& Guinle, o Hospital do Câncer e o Hospital das Clínicas da Faculdade de Medicina, numa época em que a Santa Casa dava sinais de esgotamento na assistência pública. E era necessário construir, com a participação da iniciativa privada, uma rede hospitalar para combater casos de epidemia ou doenças não tratadas na Santa Casa, principalmente a lepra e as doenças venéreas. Daqueles hospitais, apenas o primeiro foi construído em sua integridade.

O projeto para o Hospital Gaffrée \& Guinle foi desenvolvido por Porto d'Ave e seu sócio Haering, entre 1923 e 1929, data de sua inauguração. O hospital foi concebido para internar 320 pessoas e contava com um prédio principal de quatro pavimentos munido de elevador - o quarto andar era destinado ao solarium -, onde se localizavam diversos serviços e um ambulatório. Sua tipologia seguiu a do hospital higienista, com as enfermarias destacadas do corpo principal da edificação central, segundo a tradicional preocupação com a correta ventilação e insolação para o tratamento dos pacientes. Em certa medida, sua arquitetura se preparava para a tipologia que surgia nos Estados Unidos e que se tornaria hegemônica nas décadas seguintes: a do monobloco.

A estética arquitetônica acompanhava a separação das duas tipologias: a linguagem do neocolonial, predominante no Brasil da época, domina o corpo da fachada principal e os prédios menores, como a capela. Já o bloco de quatro pavimentos apresenta uma estética mais próxima de um classicismo alemão.

Nos demais projetos, Porto d'Ave se esforçaria para corresponder ao que ele entendia à época por um hospital moderno, que em sua concepção se traduzia em um hospital de função eminentemente socioeducativa, localizado em um ponto de fácil acesso e (sic) alegre e atraente (Sanglard \& Costa, 2004). Além do mais, o engenheiro tinha como referência não mais os modelos franceses, e sim os alemães e norte-americanos. Não é de se estranhar o desafio imposto a Porto d'Ave: até a década de 1930, prevalecia a tipologia do hospital pavilhonar, que seria suplantada logo depois pelo tipo monobloco. Os projetos hospitalares dos anos 1920 estavam, portanto, enfrentando um período de transição, quando mesmo os médicos hesitavam entre um modelo e outro. A própria França se mostrava dividida entre adotar um ou outro: o modelo norte-americano, constituído por instalações pavilhonares à semelhança de tendas (as tent-houses) em madeira, herdeiras das instalações tipo barraca dos hospitais-campanha, a serem queimadas todos os anos, e o modelo alemão, formado por uma única construção longilínea, equipada por balcões e galerias de cura, mais duradouro. De comum às duas tipologias, o fato de as construções estarem implantadas em um imenso parque, quase cidades-jardins.

Porto d'Ave desenvolveu dois projetos para o Hospital do Câncer (hoje Hospital Municipal Barata Ribeiro), um para o terreno próximo ao Cais do Porto e outro para o atual terreno, na Mangueira. Em ambos prevalecia a idéia de se fazer pavilhões de um a quatro pavimentos, mantendo-se a linguagem arquitetônica de linhas clássicas. Na mudança de terreno, as instalações ganharam dimensões ainda mais generosas, acentuando a planta em U, tão própria das construções hospitalares da época. Infelizmente, pouco restou desse projeto.

Pior destino teria o Hospital das Clínicas, vítima das discussões sobre a modernidade hospitalar de finais da década de 1920. Novamente Porto d'Ave faria uma série de projetos, tentando satisfazer às exigências impostas, principalmente, por João Marinho, então diretor da Assistência Hospitalar. O primeiro 
plano apresentado em 1926 previa que o hospital seria construído segundo a escola alemã, adotando prédios divididos em clínicas, alojadas em pavilhões interligados por passagens subterrâneas, mas cuja organização interna seguiria a lógica das enfermarias norte-americanas. O projeto sofreu duras críticas por parte dos adeptos do sistema monobloco, que preferiam reunir os pavilhões em uma única construção. Outras críticas foram feitas em relação a sua localização, pois uns o queriam afastado da aglomeração urbana, certamente presos às questões higiênicas mais tradicionais, que exigiam grandes terrenos em volta para a ventilação do ar, ignorando a contribuição de Tollet, e outros preferiam um terreno no Mangue, próximo ao Hospital São Francisco e à Escola de Enfermagem Anna Nery. Outro ponto de discussão foi se a maternidade deveria ficar dentro ou fora do corpo principal da construção.

Mas a polêmica principal do debate girava em torno da idéia de que, para ser um hospital verdadeiramente moderno, ele deveria abraçar sem restrições o modelo do bloco único. Marinho tinha como referência o Hospital das Clínicas de São Paulo e o Hospital de Rochester, de Nova York. Porto d'Ave, por sua vez, procuraria adotar a arquitetura do Hospital Johns Hopkins, de Baltimore, copiada em sua disposição de planta assimétrica e em sua verticalidade. Em meio às desavenças, a construção iniciou-se em 1929, mas como a obra foi definitivamente embargada em 1934, virou um grande esqueleto de armação de ferro posteriormente ocupado por moradores de baixa renda, transformando-se em favela.

Outra tendência se consagraria a partir da década de 1920: a eminente separação entre as categorias de hospital geral e hospital de isolamento. Essa separação não diria respeito apenas às terapias, mas estaria refletida igualmente na sua inserção urbana e na sua forma e linguagem arquitetônicas. O tratamento dos tuberculosos na segunda metade do século XIX exigiu hospitais de isolamento e garantiu seu uso ainda durante a prevalência do monobloco, no século seguinte, especialmente para pacientes tido como perigosos, como os portadores de hanseníase (Bittencourt, 2000).

José Messias do Carmo, em obra de 1948, discorreu sobre a definição, a característica e a organização de um hospital de isolamento. Dois hospitais serviam de modelo à época: o Hospital Pasteur de Paris e o Providence City Hospital, de Rhode Island, EUA. Para o autor, ainda se fazia necessária a construção de um grande hospital de isolamento para o Distrito Federal, pois apenas o São Sebastião, o São Francisco de Assis e o Hospital Evandro Chagas (antigo Hospital de Manguinhos) cumpriam tal função. O número de leitos deveria chegar a mil ou 1.500, mas divididos em construções com quinhentos leitos cada, situadas em área urbana e suburbana. Acima desse número, segundo Carmo, o rendimento do hospital começava a cair e sua administração se tornava árdua.

O autor, entretanto, não considerava em suas estatísticas as colônias rurais criadas no Rio de Janeiro para o tratamento de doentes que necessitavam de isolamento, implantadas na região de Jacarepaguá nas décadas de 1910 e 1920, como era o caso das colônias Juliano Moreira, para alienados, e de Curupaity, para leprosos. Vale aqui ressaltar a importância da região de Jacarepaguá na construção desses hospitais de isolamento, à semelhança do que ocorreu com os bairros do Caju e de São Cristóvão nos séculos anteriores. Em torno do morro Dois Irmãos, pertencente ao maciço da Pedra Branca e em meio à reserva primitiva da Mata Atlântica, seriam inaugurados ainda o Sanatório de Santa Maria, na década de 1940, e o Sanatório de Curicica, na década seguinte.

A terapia para tratamento dessas doenças procurava minimizar a sensação de perda da cidadania advinda da retirada dos pacientes do convívio em sociedade; tal preocupação se traduzia na criação de 
pequenos ambientes urbanos, com a reprodução de elementos típicos de uma cidade, como a praça, as residências familiares e o espaço de lazer e entretenimento, expresso na instalação de cine-teatros, clubes, salões de dança, entre outros. A arquitetura procurava acompanhar essa tentativa de se criar um ambiente familiar, adotando uma linguagem mais singela e tradicional, próxima de nossas raízes coloniais portuguesas, com construções de um pavimento e porão elevado, fazendo uso de telhados em duas águas, paredes com revestimento em baixo-relevo, geralmente na cor branca, e esquadrias de madeira. O arroubo estético ficava para as construções que abrigavam os espaços de cura, administrativos e de lazer: a linguagem utilizada foi a do art déco, cujo exemplar mais significativo está presente no cine-teatro de Curupaity.

A partir da década de 1930, caberia aos norte-americanos a primazia na adoção do sistema monobloco, aqui mencionado, ensaiado pelos alemães nas suas construções longilíneas e interligadas como uma construção única. Tal sistema, que se expressava na separação das doenças pelos diversos pavimentos de um mesmo edifício e na racionalização de circulação e trânsito de pessoal, de doentes e de material infectado, seria plenamente adotado aqui no Brasil, ao menos para os hospitais gerais inseridos na malha urbana. Podemos citar como exemplo o Hospital da Colônia Alemã, de 1934, atual Hospital da Aeronáutica, ou mesmo o Hospital dos Servidores, do mesmo ano, cujo projeto chegou a passar pelas mãos de Porto d'Ave, que viu neste a chance de projetar um legítimo hospital monobloco. ${ }^{6}$ Os hospitais de isolamento continuariam a não optar por uma tipologia única, criando um rico repertório em arquitetura para a saúde, que carece de maior atenção dos historiadores.

\section{Os Anos 1930-1940: a arquitetura hospitalar entre duas tipologias e a busca pela limpeza formal}

Nas décadas de 1930 e 1940, as discussões sobre hospital higienista, hospital de isolamento e modelos europeus caminharam para uma uniformidade: a tipologia do pavilhão de isolamento seria mantida para doenças como a tuberculose, a lepra e as de origem mental, e a do monobloco seria adotada pelos hospitais gerais, que deveriam atender aos diversos tipos de doença, segundo o padrão norte-americano.

O que se dizia à época é que os hospitais pavilhonares exigiam grande número de pessoal e altos custos de instalação e manutenção, devendo estar restritos a determinados tratamentos, como o de tuberculosos, para o qual o modelo pavilhonar era preferido ao vertical, pois suas áreas verdes e espaçosas ajudavam na recuperação dos pacientes. No entanto, os pavilhões, em sua grande maioria de um pavimento, estariam mais sujeitos aos efeitos nocivos do contato com a poeira das ruas. Na questão terapêutica, suas instalações não correspondiam à crescente individualização das doenças, restringindose aos que necessitavam de isolamento. Por fim, não se via vantagem em isolar os não contagiosos.

De fato, o monobloco apresentava muitas vantagens sobre o pavilhão, como a redução do custo da compra do terreno e instalação; a economia de transporte, de trajetos e tempo de circulação do pessoal administrativo e do corpo médico e de enfermagem, possibilitada pelo deslocamento vertical proporcionado pelos elevadores; a concentração da administração, disciplina interna e vigilância; a concentração das instalações hidráulicas, térmicas, de esgoto e de eletricidade; maior afastamento dos ruídos e da poeira para os andares mais elevados, entre outras (Brasil, 1965). Em suma, uma solução híbrida, que adotasse os dois modelos, deveria ser, então, a melhor opção. 
Duas políticas públicas de construção de hospitais e de sanatórios são importantes para se entender o que aqui se pretende analisar. Uma se refere às ações do prefeito Pedro Ernesto na primeira metade da década de 1930 e outra diz respeito à política nacional desenvolvida por Getulio Vargas em sua primeira gestão, entre 1937 e 1945. Enquanto a primeira política iria se concentrar na construção de hospitais e dispensários, a segunda, tendência mundial percebida no entre-guerras, usaria os sanatórios como principais elementos de ataque às doenças cujo tratamento dependia de isolamento. Em termos estéticos, a moderna arquitetura apresentada pelos sanatórios adotaria sem parcimônia os padrões do art déco norte-americano, ignorando a hegemonia que a estética moderna do francês Le Corbusier (1887-1965) alcançaria entre os arquitetos da geração modernista (1930-1960).

Paralelamente, a leitura do Código de Obras (decreto 6.000) lançado pelo Distrito Federal em julho de 1937 nos revela outros elementos de análise das propostas de construção dos espaços de cura, no Brasil. No decreto, os hospitais estão separados em três grandes categorias: hospitais gerais; asilos, que incluíam os hospitais de alienados, de crônicos, de tuberculosos e para doentes mentais; e 'gratuitos', talvez se referindo aos postos de assistência e aos ambulatórios. O zoneamento da cidade não permitia a construção de novos hospitais e casas de saúde nas áreas majoritariamente industriais, portuárias e comerciais, mas apenas em algumas zonas residenciais, rurais e agrícolas.

Os asilos deveriam, obrigatoriamente, possuir instalações para administração, composta de direção, secretaria e portaria; assistência, com os gabinetes médico e dentário e enfermaria; local para a permanência dos asilados, com espaços de trabalho, de leitura e recreio; alojamentos, separados para as diversas classes de pacientes, enfermeiros ou zeladores e pessoal de serviço; refeitórios, igualmente com as mesmas separações; serviços gerais, compreendendo copa, cozinha, despensa, lavanderia, incinerador de lixo etc.; velório. Para os asilos de crianças exigiam-se, ainda, instalações de campos para jogos e ginásio. O decreto ditava as dimensões dos espaços internos, altura dos pés-direitos (3,2 m) e o que deveria constar em cada enfermaria: salas de curativo, tratamento e serviços médicos; copa; rouparia; pequena farmácia e instalações sanitárias e banheiros.

Para os hospitais, era obrigatório que o programa contasse com cozinha, lavanderia, necrotério e incineradores de lixo. O decreto, além de estabelecer diretrizes quanto ao tamanho dos pés-direitos, um pouco mais baixos que para os sanatórios $(3,0 \mathrm{~m})$, dos corredores e dos espaços internos, exigia o uso de matérias resistentes, impermeáveis e laváveis, como cerâmicas e ladrilhos, nos pisos e nas paredes, até a altura de 1,5 m, para os corredores de circulação, banheiros e cozinhas. Nas construções com mais de dois pavimentos, deveriam ser instalados elevadores. Os dormitórios de doentes deveriam obedecer à melhor orientação solar, protegendo os vãos, como janelas e portas, da incidência do sol, por meio de varandas, marquises e anteparos naturais, como vegetação, ou artificiais, como persianas. As construções deveriam ainda permitir a ventilação permanente dos dormitórios, aproveitando a melhor direção dos ventos oferecida pelo terreno. O decreto traduzia e reunia, assim, séculos de experiência na construção de espaços de cura, preparando-os para a modernidade, de forma mais organizada.

Na gestão de Pedro Ernesto na Prefeitura do Distrito Federal adotou-se um plano de construção de hospitais policlínicos regionais e de dispensários, entre 1931 e 1934. À frente da construção desses hospitais estava Luiz Moraes Jr., o mesmo construtor de Manguinhos. A sua Companhia Industrial Construtora do Rio de Janeiro, em sociedade com Archimedes d'Arthagnam Saldanha, realizou a maioria das obras. 
A linguagem plástica adotada nesses edifícios almejava uma modernidade ainda embrionária, com fortes referências ao art déco de origem norte-americana, sendo identificada como um 'protomodernismo'; procurava, à sua maneira, romper com os 'estilos' até então adotados para as construções hospitalares, que ora faziam referências ao gótico alemão, ora ao neoclássico, ora ao romantismo francês. O que se buscou foi a limpeza formal, com destaque para as varandas, sem abandonar por completo o uso de esquinas e acessos destacados, de ornamentação, minimamente reduzida a frontões estilizados, e de marcações e linhas cubistas.

Por sua vez, a Divisão de Obras do Ministério de Educação e Saúde atuou entre 1934 e 1953, e depois até 1977, para o Ministério da Saúde, na construção de edifícios para todo o país, como responsável por elaborar os programas arquitetônicos, os projetos, organizar as especificações e os orçamentos, executar e fiscalizar as obras (Oliveira, Costa \& Pessoa, 2003). Ao longo desse período, a equipe projetou e construiu, com verbas do ministério, de 13 a 19 grandes sanatórios em praticamente todos os estados da nação, incluindo o de Santa Maria, em Jacarepaguá (1937-1943). ${ }^{7}$ Em Porto Alegre, construiu o Hospital Sanatório Belém, em parceria com a sociedade filantrópica de mesmo nome. Essa estratégia de criação de leitos para o tratamento de tuberculosos contou com hospitais especializados e hospitais, entre privados e públicos, que mantinham leitos para esses doentes, o que ficou caracterizado como a Cruzada Sanitária da Era Getuliana. A linguagem arquitetônica, dependendo do autor do projeto - entre eles, certamente, Jorge Ferreira -, se apresentava mais ousada, adotando a estética proposta por Le Corbusier: ausência de ornamento, estrutura aparente, planta livre, a idéia do protótipo e a possibilidade de reprodução industrial (Cavalcanti, 2006).

Outra equipe foi a de Engenharia e Arquitetura da Campanha Nacional Contra a Tuberculose (CNCT), criada em 1946, sob a orientação e fiscalização do Serviço Nacional de Tuberculose, do Departamento Nacional de Saúde do Ministério da Educação e Saúde (MES). Essa equipe contava em seus quadros com arquitetos como Sérgio Bernardes e Jorge Machado Moreira, que, como Jorge Ferreira, adotavam mais claramente uma estética corbusiana.

A campanha atuava no combate principalmente da tuberculose do tipo óssea e do tipo pulmonar. Para cada doença um modelo de terapia, com especial reflexo na arquitetura. Para o tratamento da tuberculose do tipo óssea era recomendada a helioterapia, que consistia, basicamente, na exposição do doente ao sol, por várias horas ao dia. E para a pulmonar, o mais importante eram o ar e a ventilação. Para podermos comparar um modelo com o outro, tomemos como exemplos o Sanatório de Santa Maria, para o primeiro caso, e o de Curicica para o segundo. O de Santa Maria foi projetado pela equipe da Divisão de Obras, entre 1937 e 1943, e o de Curicica pelo escritório de engenharia e arquitetura da CNCT, entre 1949 e 1952, tendo à frente Sérgio Bernardes.

Para o Sanatório de Santa Maria, foi adotada a construção em monobloco, situada em uma grande área verde. Sua planta consiste na junção de dois Ys, esquema comum a esses sanatórios, que se utilizavam também da planta em V, como forma de evitar os efeitos dos ventos fortes, que, nesse caso, eram prejudiciais ao tratamento (Bittencourt, 2000). As varandas de cura posicionavam-se nas 'pernas' dos Ys, e no centro ficavam as áreas comuns, como administração, salas de cirurgia, cozinha, lavanderia etc. As varandas são o ponto de destaque da edificação: lugar de exposição ao sol e da contemplação do sítio circundante. 
No Sanatório de Curicica, por sua vez, preferiu-se o tradicional sistema de pavilhões de um pavimento espalhados por uma extensa área verde, embora pelo mundo esse sistema estivesse em franco desuso. Reconhecia-se nessa tipologia um fator importante para o tratamento da tuberculose pulmonar, além de forma de evitar o estado de reclusão percebido nos doentes internados nos sanatórios em monoblocos, o que levou a CNCT a projetar o conjunto sanatorial com aquelas características.

O programa arquitetônico seguiu as premissas técnicas elaboradas pelo Serviço Nacional da Tuberculose, previamente aprovado pelo MES, cujas recomendações gerais seguiam o estudo e a padronização da construção de sanatórios e dispensários tipo campanha: eficiência, baixo custo e manutenção econômica, sem, entretanto, sacrificar suas qualidades técnicas, funcionais e arquitetônicas. Era preciso igualmente dotar suas instalações de espaços que favorecessem a capacitação profissional e o convívio social dos doentes, por meio de oficinas, áreas de lazer, de culto religioso e de entretenimento.

Como vimos, ao longo da década de 1930 até os anos 50, os sistemas pavilhonar e monobloco disputavam a preferência de médicos e arquitetos nas modernas construções para a saúde, com predominância dos primeiros, mesmo diante da grande diversidade de categorias de hospitais então verificada. ${ }^{8} \mathrm{O}$ ano de 1967 , entretanto, seria definitivo para a mudança desse quadro.

\section{Anos 1950-60: o hospital tecnológico e a triunfante arquitetura monobloco vertical}

A década de 1950 foi exemplar para a discussão do que seria considerado um moderno hospital, conduzida, dessa vez, por arquitetos. Usamos como base a publicação de 1954 da Comissão de Planejamento de Hospitais do Instituto de Arquitetos do Brasil, departamento de São Paulo (IAB-SP). Essa publicação, Planejamento de Hospitais, foi fruto das aulas e dos debates realizados por ocasião do curso de Planejamento de Hospitais oferecido pelo instituto entre 13 e 17 de abril de 1953, em São Paulo, do qual participaram arquitetos, engenheiros, médicos, enfermeiras e estudantes das respectivas áreas.

Os objetivos desse curso, segundo consta na introdução da publicação, eram, entre outros, "divulgar conquistas no campo de planejamento de hospitais, analisar os elementos essenciais a um projeto são e científico, possibilitar a construção de hospitais eficientes (...), aproximar interessados, e estimular o intercâmbio de informações e pesquisa" (Prado, Karman \& Levi, 1954: 13-14).

Quanto à maior contribuição do arquiteto, Rino Levi, um dos participantes do curso, tinha consciência de que esta se daria na forma plástica final do projeto, como em qualquer outro projeto arquitetônico. Mas, no caso do hospital, a estética estava aliada a uma vontade de organizar um serviço que, na sua opinião, contribuiria para uma investigação científica mais ampla, em substituição a controvérsias e a critérios pessoais e empíricos no planejamento de um programa dos mais complexos (Levi, 1954).

Para os participantes em geral, a grande contribuição da arquitetura moderna seria transformar o hospital em uma construção monobloco, onde se poderia demonstrar todo o rigor de uma construção sólida, imponente, digna de uma arquitetura racional, bem planejada e bem construída. Uma construção que se preocupasse com a localização na malha urbana existente, com a insolação, a ventilação, as circulações, os fluxos, a estrutura, as instalações e os detalhes.

Os edifícios hospitalares em monobloco construídos no Rio de Janeiro nos anos 1950 procurariam seguir tais recomendações, a exemplo dos hospitais da Lagoa; dos Radialistas; do Câncer, na praça da 
Cruz Vermelha; de Ipanema; do Andaraí e das Clínicas da Faculdade de Medicina, que se revelaram bons projetos.

O Hospital da Lagoa, projetado por Oscar Niemeyer e Hélio Uchoa, com paisagismo de Burle Marx, passa para a historiografia brasileira como a grande expressão de hospital da tipologia monobloco do período moderno. Seus detalhes arquitetônicos, como o pilar em V e a estrutura em arco do bloco do auditório, revelam grande apuro técnico e estético. Especialmente importante, o pilar, criação de Niemeyer baseada no repertório formal lançado pelo modernismo internacional, foi primeiramente utilizado nesse hospital, merecendo a atenção do historiador francês Yves Bruand (1981). A edificação do Hospital da Lagoa é um dos poucos exemplares modernos tombados por um organismo de proteção patrimonial e tem sua importância no rigor com que nela foram aplicados os preceitos de um moderno hospital monobloco.

As doenças foram separadas por seus dez pavimentos; a circulação de doentes, pessoal e de serviço foi facilitada pela construção de amplos corredores e de um prisma de circulação vertical, destacado do bloco principal. As áreas destinadas ao convívio social foram localizadas no térreo. Os quartos dos doentes, as salas dos médicos e de operação foram posicionados para a melhor insolação e a melhor vista, de frente para a lagoa Rodrigo de Freitas. As salas de serviço ficaram voltadas para a rua Jardim Botânico; para proteção contra o sol, adotaram-se tijolos vazados e brise-soleils verticais.

Em 1957, foi desenvolvido pelo Escritório Técnico da Universidade do Brasil (ETBU), sob a chefia de Jorge Machado Moreira, o projeto do Hospital Universitário Clementino Fraga Filho, para o então Hospital de Clínicas da Universidade do Brasil. Projetada para atender ao programa de um hospital-escola com dois mil leitos, foi construída uma grandiosa estrutura de $220.000 \mathrm{~m}^{2}$, adotando a tipologia do hospital monobloco. Mas, ainda hoje, funciona apenas metade de suas instalações, localizadas na ilha do Fundão.

Tal projeto seria a grande referência para o hospital monobloco no Rio de Janeiro e no Brasil, juntamente com o do Hospital das Clínicas de São Paulo e o de Porto Alegre, ambos de Moreira. Um dos autores da Comissão do Plano da Universidade do Brasil, e posteriormente ministro da Educação, Ernesto de Souza Campos, chegou a afirmar, no prefácio da reedição da obra História e Evolução dos Hospitais, usando os projetos de Moreira como referência, que a década de 1950 foi o período da renovação hospitalar, o que obrigou especialmente os arquitetos a debaterem o assunto (Campos, 1965). Publicada primeiramente em 1944, a cargo da Divisão de Organização Hospitalar do Departamento Nacional de Saúde, essa obra traria importantes contribuições para o debate, abrindo um campo de reflexão sobre a construção de hospitais e sua arquitetura especializada e extremamente funcional. Criada em 1941, com base no modelo do American College of Surgeons, a divisão se tornou uma referência para o tema, especialmente nas duas décadas seguintes, ao oferecer cursos de Organização e Administração Hospitalares, a exemplo que faria o IAB em 1953-1954.

Para o arquiteto Jarbas Karman (1954: 175), diretor do curso oferecido pelo IAB, o hospital moderno era "uma das mais complexas, dinâmicas e especializadas instituições. Dia a dia, novas aplicações, pesquisas e descobertas o vêm transformando. Gradativamente, o que ainda resta de empírico e tradicional dará lugar ao científico e ao racional".

Karman baseava suas impressões nos estudos da Divisão Hospitalar do Serviço de Saúde Pública dos Estados Unidos (U.S. Public Health Service). Em seu texto, o arquiteto se preocupava não somente com a solução plástica final, uma combinação de elementos formais de diversos tipos de plantas arquitetônicas 
(em I, L, V, U, X, Y), mas também com itens que vão desde a disposição interna de cada aparelho, sala, centro médico e cirúrgico, associada ao detalhamento das medidas de cada espaço e cada área de circulação - vertical e horizontal, fluxos -, áreas limpas, áreas sujas, sociais e de serviço, enfermarias gerais e de isolamento, até o detalhamento de armários, portas, sistemas de ventilação, instalações etc., demonstrando a extrema complexidade de uma construção hospitalar contemporânea à época.

Em 1967, o governo federal proibiu a criação de novos leitos para tuberculosos e os hospitais gerais passaram a oferecer tratamento para esses doentes, o que exigiu reformas e ampliações em suas instalações, na maioria obsoletas. Essas reformas se concentraram na construção de monoblocos anexos ou em substituição aos antigos edifícios, grandes lâminas verticais de cinco, sete ou dez pavimentos. Podemos citar como exemplos os hospitais Salgado Filho, Rocha Faria, Getulio Vargas, Miguel Couto, Souza Aguiar, Pedro II e Carlos Chagas.

As discussões da década anterior seriam plenamente aproveitadas e o monobloco, enfim, reinava absoluto.

\section{Arquitetura e Medicina: entre a teoria e a prática}

Como procuramos evidenciar aqui, há muito ainda que se refletir sobre as relações entre arquitetura e saúde. A arquitetura pode ser entendida como materialização da evolução da cultura humana, juntamente com a escultura, se expressando por meio de suas formas e espaços construídos. Na saúde, os maiores desafios se impuseram na tentativa de aliar os preceitos da medicina com os materiais construtivos utilizados à época, a geografia, o clima e a expressão plástica. Das construções feitas à semelhança de igrejas e templos religiosos aos edifícios compactos e extremamente funcionais, construídos no coração das cidades ou fora delas, investidos de missões de caridade ou sanitárias e higiênicas, os espaços de saúde, em especial os hospitais, sempre estiveram permeados por seu contexto político, social, econômico, médico e arquitetônico.

$\mathrm{O}$ que pretendemos analisar aqui foi o modo como os arquitetos, engenheiros e construtores, associados aos médicos até um determinado momento, procuraram responder, entre a prática e a teoria e com razão e engenhosidade, aos desafios da construção de espaços de saúde no Rio de Janeiro. Como vimos, a salubridade das águas, do ar e do lugar sempre foram determinantes para uma boa arquitetura. Especialmente para os hospitais, casas de saúde e sanatórios, a fórmula de uma boa arquitetura acrescenta o diálogo afinado com as teorias médicas.

Em comum com outras cidades do Novo Mundo, a história da arquitetura hospitalar se iniciou entre nós na relação de cumplicidade primeiramente com a religiosidade. Aos poucos, os espaços, ao mesmo tempo que se transformavam de ambientes de morte em ambientes de cura, foram ganhando autonomia, inclusive formal. Subordinados à busca por amplos espaços, externos e internos, e procurando contribuir no combate a uma cada vez maior individualização das doenças e de seus tratamentos, os espaços de saúde procuraram multiplicar e aperfeiçoar os ambientes de cura, almejando excelência terapêutica.

A arquitetura se propôs a acompanhar esses desafios. Quando a função do hospital era amparar o doente até a morte, expressava-se como legítimos monastérios, de construção sólida e robusta, lugar de recolhimento e contemplação. Diante da necessidade de buscar melhores condições para a recuperação 
e cura de seus pacientes, a arquitetura hospitalar procurou se tornar mais leve, abrindo vãos e pátios, aumentando a altura dos pés-direitos internos, descobrindo e adotando materiais e recursos construtivos para o melhor aproveitamento do ar e do sol saudável. No Rio de Janeiro, os hospitais deveriam seguir as direções NNE e NNO, a direção mais satisfatória - verão e inverno - para se proteger da insolação, preceito conhecido desde os primeiros estudos de Vicente Licínio Cardoso (1927) realizados na década de 1920 acerca da arquitetura hospitalar. ${ }^{9}$

A resposta estética apareceu inicialmente na forma ordenada e harmoniosa da arquitetura clássica, conjugada com a arquitetura francesa dos challets: ritmo e austeridade convivendo com rendilhados, venezianas, azulejos, ladrilhos hidráulicos e painéis decorativos. Depois, com a modernidade impondo respostas cada vez mais eficazes, os locais de saúde passaram a rejeitar os rebuscamentos, adotando o lema "menos é mais", ${ }^{10}$ e a se concentrar na eficiência de seus espaços e no propósito de suas construções, sempre aliados ao diálogo com as indicações médicas, no caso das construções hospitalares. Se o tratamento exigia mais contato com o sol, construíam-se sanatórios de amplas varandas. Se o objetivo era usufruir mais do ar saudável, mantinham-se os pavilhões espalhados por grande área verde. Se o sol precisava ser controlado, evitava-se a exposição exagerada, usando-se os recursos das persianas, tijolos vazados, marquises, vegetação natural. Se a idéia era evitar a poeira e o barulho das ruas, elevava-se a construção, criando-se verdadeiros arranha-céus da saúde.

As linguagens arquitetônicas se expressaram das mais variadas formas, indo da referência à cultura clássica ao modo de vida elegante das casas francesas, do colonialismo português aos hospitais-cidade alemães e às perenes tent-houses americanas, do protomodernismo americano ao racionalismo europeu, sem que isso, insistimos, tenha representado uma evolução linear e progressiva. Hoje se reconhece que o ponto fraco dos hospitais verticais e compactos está em não aproveitar o melhor contato com o ambiente externo, o que os torna sempre dependentes de mecanismos artificiais. Busca-se a volta ao uso de jardins e do ar natural para uma melhor recuperação dos pacientes.

A cidade do Rio de Janeiro conta com bons exemplos de bens imóveis relacionados à saúde registrados em livros de tombo por seu valor histórico e/ou arquitetônico, englobando variadas linguagens e períodos construtivos. Graças à atuação das três instâncias de proteção, federal, estadual e municipal, temos protegidos o Hospital da Santa Casa da Misericórdia, o Hospital das Crianças da Santa Casa da Misericórdia, o Núcleo Histórico da Fiocruz, o conjunto da antiga Colônia Juliano Moreira, os hospitais São Francisco de Assis, Moncorvo Filho, da Cruz Vermelha, da Lagoa, Gaffrée \& Guinle, Frei Antonio, Ordem Terceira da Penitência, o conjunto da Beneficência Portuguesa, a Escola de Enfermagem Anna Nery, a Caixa de Socorros D. Pedro V, o Instituto Nacional de Educação de Surdos e a Casa de Saúde Dr. Eiras.

Esse repertório, em grande medida ainda não totalmente difundido, somado ao estudado nesta publicação, precisa ter seu devido valor reconhecido e elevado à categoria de patrimônio cultural da saúde da cidade do Rio de Janeiro. 


\section{Notas}

${ }^{1}$ Rino Levi (1901-1965) realizou em São Paulo os projetos da Maternidade da Universidade de São Paulo, em 1945, do Hospital Central do Câncer, 1947, do Hospital da Cruzada Pró-Infância, 1950, do Hospital Albert Einstein, 1958; na Venezuela, os do Hospital Central de Caracas, 1959, de Maiquetia, 1959, e de Puerto Cabello, 1960 (Anelli, Guerre \& Nelson, 2001).

2 Por partido arquitetônico entende-se um conjunto de diretrizes que norteiam a elaboração do projeto de arquitetura, incluindo opção estética, definição de uso, elementos construtivos, recursos etc.

${ }^{3}$ Conforme descrição arquitetônica elaborada por Inês El-Jaick Andrade para o verbete do Hospital São Francisco de Assis, para esta publicação (no CD-ROM encartado).

${ }^{4} \mathrm{~A}$ autora se refere aos médicos exploradores, aqueles que participavam de viagens empreendidas no contexto de empresas colonialistas européias; tais profissionais realizavam um amplo mapa nosográfico dos países situados nas colônias, a chamada geografia médica.

${ }^{5}$ Luiz Moraes Jr. se tornaria grande referência em arquitetura para a saúde no Rio de Janeiro na primeira metade do século XX. Sua aproximação com a área deveu-se ao convite de Oswaldo Cruz para a realização dos projetos dos edifícios do então Instituto Soroterápico (1905-1917). A relação do arquiteto com o instituto foi mantida na gestão de Carlos Chagas (1917-1934). Além das obras em Manguinhos, Moraes seria o responsável pelo projeto e construção da Policlínica da Avenida Central (1904), do Desinfectório de Botafogo (atual Hospital Rocha Maia, 1905), pelas reformas do Hospital do Engenho de Dentro (1908), pelos projetos de novos pavilhões, reforma e construção de pavilhões do Hospital São Sebastião (1908) e de Jurujuba (1909). Já a inserção de Porto d'Ave na arquitetura hospitalar deveu-se ao mecenato de Guilherme Guinle. A aproximação entre eles foi facilitada pelo fato de sua cunhada Gilda ter sido casada com Carlos Guinle, irmão de Guilherme. Na década de 1920, Guilherme Guinle financiou a construção de três hospitais para a saúde pública, durante a gestão de Carlos Chagas no DNSP (Sanglard, Costa \& Mello, 2007).

${ }^{6}$ Porto D'Ave foi vencedor em concurso de arquitetura realizado em 1934 para o Hospital dos Servidores. Todavia, a construção do hospital se arrastou por uma década e o projeto construído sofreu modificações, cabendo sua autoria final ao engenheiro Dulphe Pinheiro Machado, com colaboração do médico Felix Lamela (Sanglard \& Costa, 2007).

7 Segundo dados do Fundo Gustavo Capanema, do Centro de Pesquisa e Documentação História Contemporânea do Brasil da Fundação Getulio Vargas (Cpdoc/FGV), foram projetados sanatórios para tuberculosos nos estados do Distrito Federal (Sanatório de Santa Maria, em Jacarepaguá), Pará (Sanatório de Belém, 1938), Pernambuco (Sanatório Otávio de Freitas, em Recife, 1939-1946), Ceará (Sanatório de Fortaleza, 1938), Espírito Santo (Sanatório Getulio Vargas, em Vitória, 1938-1942), Rio de Janeiro (Sanatório Azevedo Lima, em Niterói, 1939-1946), Rio Grande do Norte (Sanatório de Natal, 1939), Maranhão (Sanatório de São Luis, 1939), Sergipe (Sanatório de Aracaju, 1939-1941), Alagoas (Sanatório General Severiano da Fonseca, em Maceió, 1939-1946), São Paulo (Sanatório de Mandaqui, 1939), Paraíba (Sanatório Clementino Fraga, 1941-1946), Piauí (anexo ao Hospital Getulio Vargas, 1941-1944), Minas Gerais (Sanatório Getulio Vargas, projetado mas não construído), Mato Grosso (Sanatório de Campo Grande, projetado mas não construído), Bahia (Sanatório São Gonçalo dos Campos, projetado mas não construído), Goiás (projetado mas não construído), Amazônia (projetado mas não construído) e Acre (projetado mas não construído).

${ }^{8}$ Segundo publicação do IAB, Planejamento de Hospitais (Prado, Karman \& Levi, 1954), a assistência hospitalar se dividia em geral e especializada. Além dos hospitais gerais e especializados, eram considerados especiais os hospitais do tipo colônia, vila, asilo, sanatório, prisão, de emergência, móvel, de ensino e navio. Na mesma publicação propunha-se uma nova classificação mais simples: hospitais do tipo clínica ou policlínica, dispensário, ambulatório, estância de cura, asilo, abrigo, albergue, hidromineral, termal, balneário e climático. Para os hospitais especializados, entretanto, propunha-se uma classificação detalhada que abrangia trinta itens diferentes, entre aqueles destinados a doenças cardíacas; doenças transmissíveis; câncer; doenças mentais; da garganta, nariz e ouvidos; maternidade; para crianças, velhos, surdos-mudos, aleijados etc.

${ }^{9}$ Cito o trabalho de Vicente Licínio Cardoso, em tese apresentada ao concurso para professor da Escola Politécnica, na cátedra de Arquitetura e Construção Civil. Em 1927, Cardoso escreve os Princípios Geraes Modernos de Hygiene Hospitalar, em que traça a evolução do hospital moderno a partir de 1786, com o surgimento do hospital pavilhonar na França, em reação aos tipos herdados da Idade Média e da Renascença, até os melhores exemplos de hospitais nos Estados Unidos, chegando a analisar especificamente as construções cariocas.

${ }^{10}$ Lema preconizado por Adolf Loos em 1908, quando do lançamento de sua publicação Ornamento e Crime, onde ele desenvolve os princípios do modernismo que levou à rejeição do ornamento como elemento compositivo e formal. 


\section{Referências}

ANELLI, R.; GUERRA, A. \& NELSON, K. Rino Levi: arquitetura e cidade. São Paulo: Romano Guerra Editora, 2001.

BITTENCOURT, T. Peste Branca, Arquitetura Branca: os sanatórios de tuberculose no Brasil na primeira metade do século vinte, 2000. Dissertação de Mestrado, São Carlos: Instituto Escola de Engenharia, Universidade de São Carlos.

BRASIL. Código de Obras e Legislação Complementar. Decreto 6.000, de 1 de julho de 1937.

BRASIL. História e Evolução dos Hospitais [1944]. Rio de Janeiro: Divisão de Organização Hospitalar/Departamento Nacional de Saúde/Ministério da Saúde, 1965.

BRUAND, Y. Arquitetura Contemporânea no Brasil. São Paulo: Perspectiva, 1981.

CAMPOS, E. S. Proêmio. In: BRASIL. História e Evolução dos Hospitais [1944]. Rio de Janeiro: Divisão de Organização Hospitalar/Departamento Nacional de Saúde/ Ministério da Saúde, 1965.

CARDOSO, V. À Margem da Arquitetura Grega e Romana e Princípios Geraes Modernos de Hygiene Hospitalar. Rio de Janeiro: Typographia do Anuário do Brasil, 1927.

CARMO, J. Contribuição ao Estudo da Evolução do Hospital em Higiene Pública, 1948. Tese apresentada para concurso de professor catedrático de higiene e legislação farmacêutica na Faculdade Nacional de Farmácia da Universidade do Brasil.

CAVALCANTI, L. Moderno e Brasileiro: a história de uma nova linguagem na arquitetura (1930-1960). Rio de Janeiro: Jorge Zahar, 2006.

DESAI, M. Docomomo Journal, n. 35, p. 11, set. 2006.

FAURE, O. Histoire Sociale de la Médecine (XVIII ${ }^{e}$ XXè siècles). Paris: Anthropos Histhoriques, 1994.

FOUCAULT, M. Microfísica do Poder. 17. ed. Rio de Janeiro: Graal, 1999.

História e Patrimônio Cultural da Saúde. Termo de constituição da Rede de História e Patrimônio Cultural da Saúde. Casa de Oswaldo Cruz. Rio de Janeiro, set. 2006. (Mimeo.)

KARMAN, J. B. Unidade de centro cirúrgico e centro de material e de esterilização. In: PRADO, A. C.; KARMAN, J. B. \& LEVI, R. Planejamento de Hospitais. São Paulo: IAB-SP, 1954.

LEVI, R. Planejamento de hospitais sob o ponto de vista do arquiteto. In: PRADO, A. C.; KARMAN, J. B. \& LEVI, R. Planejamento de Hospitais. São Paulo: IAB-SP, 1954.

MACHADO, R. et al. Danação da Norma: medicina social e constituição da psiquiatria no Brasil. Rio de Janeiro: Graal, 1978.

MIQUELIN, L. C. Anatomia dos Edifícios Hospitalares. São Paulo: Cedas, 1992.

MIGNOT, C. Architecture of the $19^{\text {th }}$ Century. Colonia: Evergreen, 1983.

MORAIS, R. A geografia médica e as expedições francesas para o Brasil: uma descrição da estação naval do Brasil e da Prata (1868-1870). História, Ciências, Saúde-Manguinhos [on-line], 14(1): 39-62, 2007. Disponível em: <www.scielo.br/scielo.php?script=sci_arttext\&pid=S0104-59702007000100003\&lng=pt\&nrm=iso $>$. Acesso em: 13 nov. 2007.

OLIVEIRA, B.; COSTA, R.; PESSOA, A. Um Lugar para a Ciência: a formação do campus de Manguinhos. Rio de Janeiro: Editora Fiocruz, 2003.

PÔRTO, A. \& OLIVEIRA, B. Edifício colonial construído pelos jesuítas é lazareto desde 1752 no Rio de Janeiro. História, Ciências, Saúde - Manguinhos [on-line], 2(3): 171-174, 1996. Disponível em: <www.scielo.br/ scielo.php?script=sci_arttext\&pid=S0104-59701996000400009\&lng=pt\&nrm=iso $>$. Acesso em: 13 nov. 2007.

PRADO, A. C.; KARMAN, J. B.; LEVI, R. Planejamento de Hospitais. São Paulo: Instituto de Arquitetos do Brasil de São Paulo, 1954.

RUSSEL-WOOD, A. Fidalgos e Filantropos: a Santa Casa da Misericórdia da Bahia, 1550-1755. Brasília: Editora UnB, 1981.

SANGLARD, G. \& COSTA, R. G. R. Direções e traçados da assistência hospitalar no Rio de Janeiro, $1923-1931$. História, Ciências, Saúde - Manguinhos, 11(1):107-141, 2004. 
HISTÓRIA DA SAÚDE NO RIO DE JANEIRO

SANGLARD, G. \& COSTA, R. G. R. (Orgs.) Porto d'Ave: projetos para a saúde. Catálogo exposição, 2007.

SANGLARD, G.; COSTA, R. G. R. \& MELLO, M. T. B. A coleção Porto d'Ave e a assistência hospitalar no Rio de Janeiro, 1920. Revista do Instituto Histórico e Geográfico Brasileiro, 435: 195-208, 2007.

TOLEDO, L. Feitos para Curar: arquitetura hospitalar e processo projetural no Brasil. Rio de Janeiro: ABDEH, 2006.

TOLLET, C. Les Édifices Hopitaliers: depuis leur origine jusqu'à nos jours. 10 ed. Paris: s. n., 1892

TUNDIS, S. \& COSTA, N. Cidadania e Loucura: políticas de saúde mental no Brasil. Rio de Janeiro: Vozes, 1990.

Bibliografia complementar

COSTA, R. Healthcare in Brazil. 1930-1960: preserving the modern architectural legacy. Docomomo Journal, n. 37, Sept. 2007.

CREMNITZER, J-B. Architecture et Santé: les temps du sanatorium en France et Europe. Éditions A. et J. Picard, 2005.

NASCIMENTO, D.; COSTA, R.; PESSOA, A.; MELLO, E. Sanatório de Curicica: um Sérgio Bernardes pouco conhecido, 2003. Disponível em: <www.vitruvius.com.br>.

RIBEIRO, L. A Luta contra a Tuberculose no Brasil: apontamentos para a sua história. Rio de Janeiro: Editorial SulAmericana, 1956.

SEGAWA, H. Arquitetura na Era Vargas: o avesso da unidade pretendida. In: PESSOA, J. et al. (Orgs.) Moderno e Nacional. Niterói: EdUFF, 2006. 


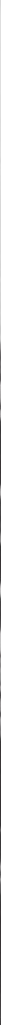

Vista da Exposição, 1922. Foto Augusto Malta. Acervo Arquivo Geral da Cidade do Rio de Janeiro

Vista do morro do Castelo para o Hospital Geral da Santa Casa, mostrando a disposição dos pátios internos da construção neoclássica e sua localização privilegiada.

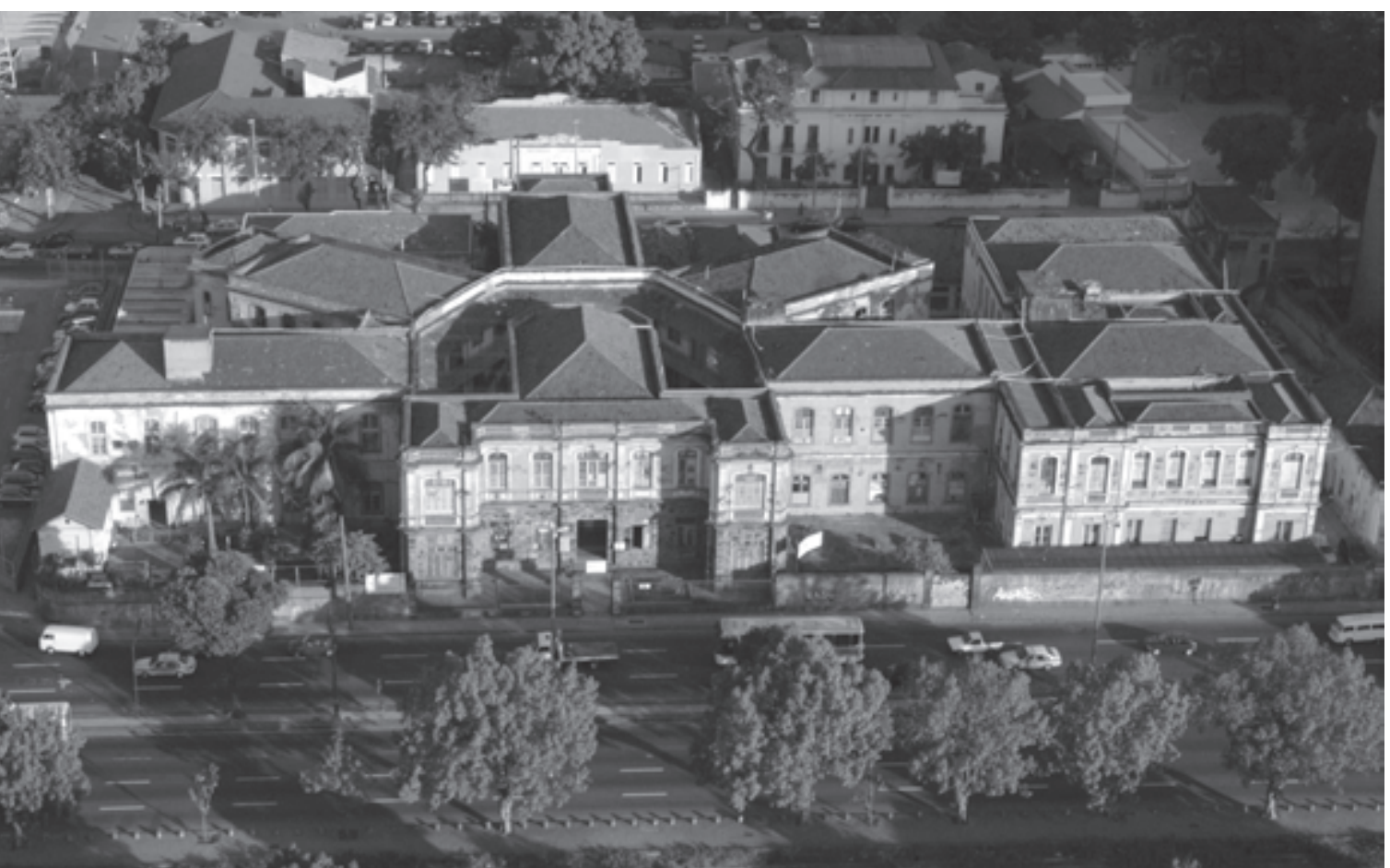

Hospital São

Francisco de

Assis, [s.d.]. Acervo

Universidade

Federal do Rio de

Janeiro

Vista aérea do

conjunto

evidenciando a

disposição dos

pavilhões em

forma radial

(paróptico). 


\section{Hospital São}

Sebastião, [s.d.].

Fonte: Oswaldo

Cruz Monumenta Histórica. Acervo

Biblioteca da

Casa de Oswaldo

Cruz/Fiocruz

Interior de um dos pavilhões de isolamento do Hospital São Sebastião. Em destaque, à esquerda, as telas de separação para os leitos dos pacientes infectados.
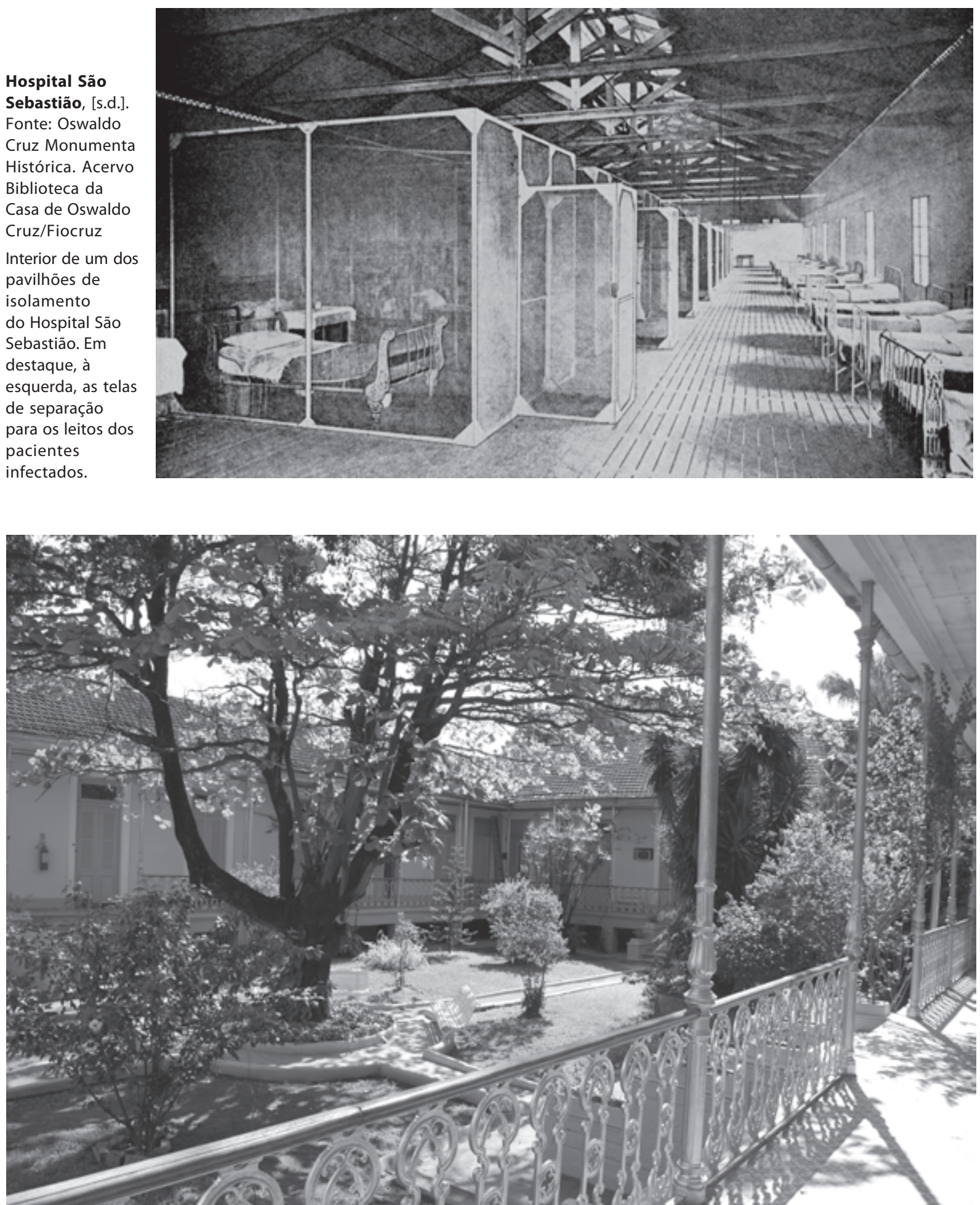

Hospital Evangélico, 2008. Foto Roberto Jesus Oscar e Vinícius Pequeno. Acervo Casa de Oswaldo Cruz

Vista do pátio interno do Hospital Evangélico, criado para facilitar a aeração e a ventilação dos quartos, proposta clara da tipologia dos hospitais higienistas. 


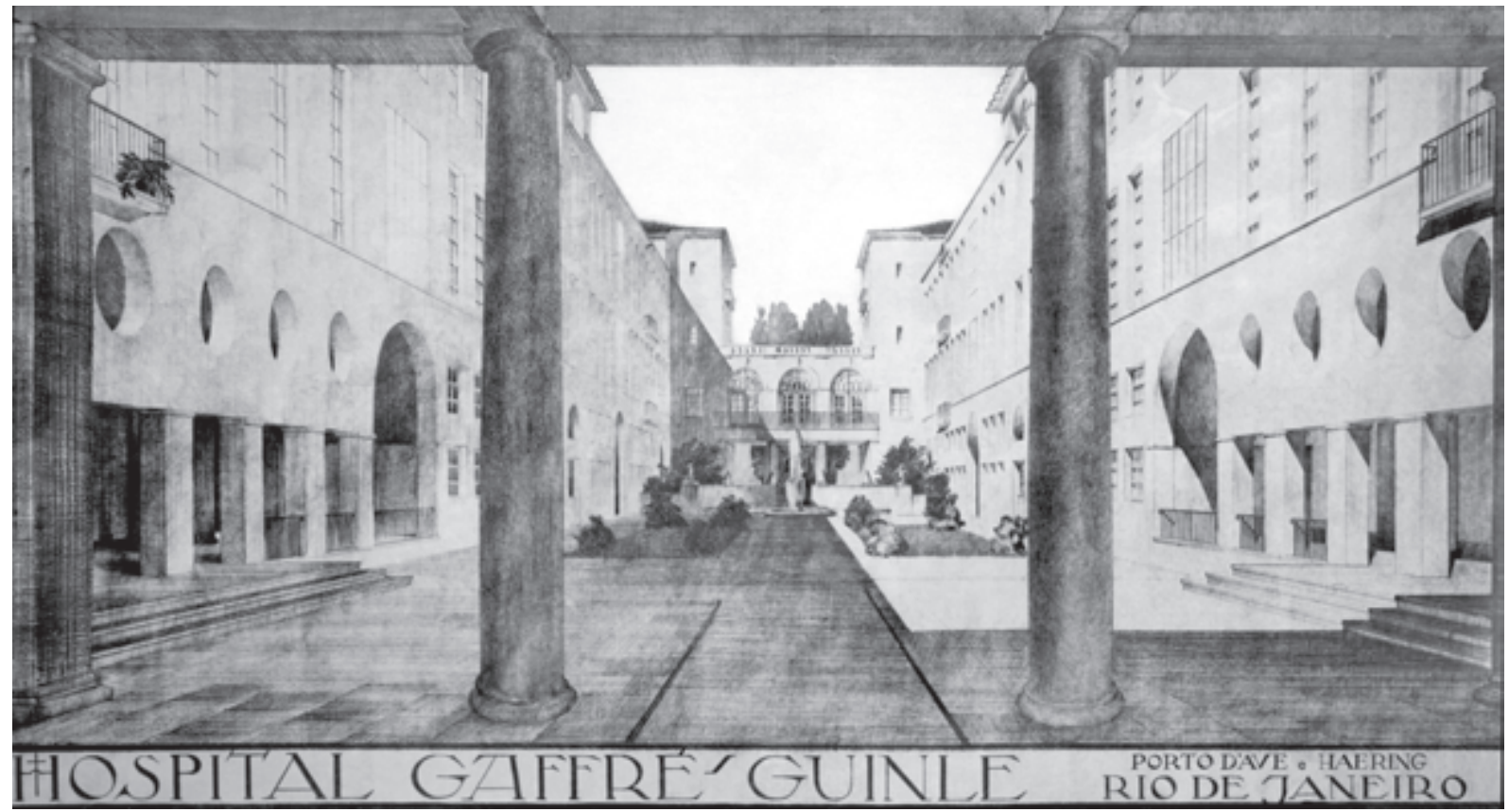

Hospital Gaffrée \& Guinle, [1924-1929]. Acervo Casa de Oswaldo Cruz

Vista do pátio interno do Hospital Gaffrée \& Guinle. Neste desenho percebe-se a utilização de elementos formais mais modernos, preteridos por um estilo mais tradicional de arquitetura, expresso na linguagem neocolonial. Projeto de Porto d'Ave e Haering.

Pavilhão de Diversões, Colônia de Curupaity, [s.d.]. Acervo Cpdoc/FGV Vista do Pavilhão de Diversões da Colônia de Curupaity, exemplar da arquitetura art déco, que neste espaço de entretenimento adota linguagem arquitetônica diferenciada em relação à dos demais edifícios propostos para o hospital-colônia. 


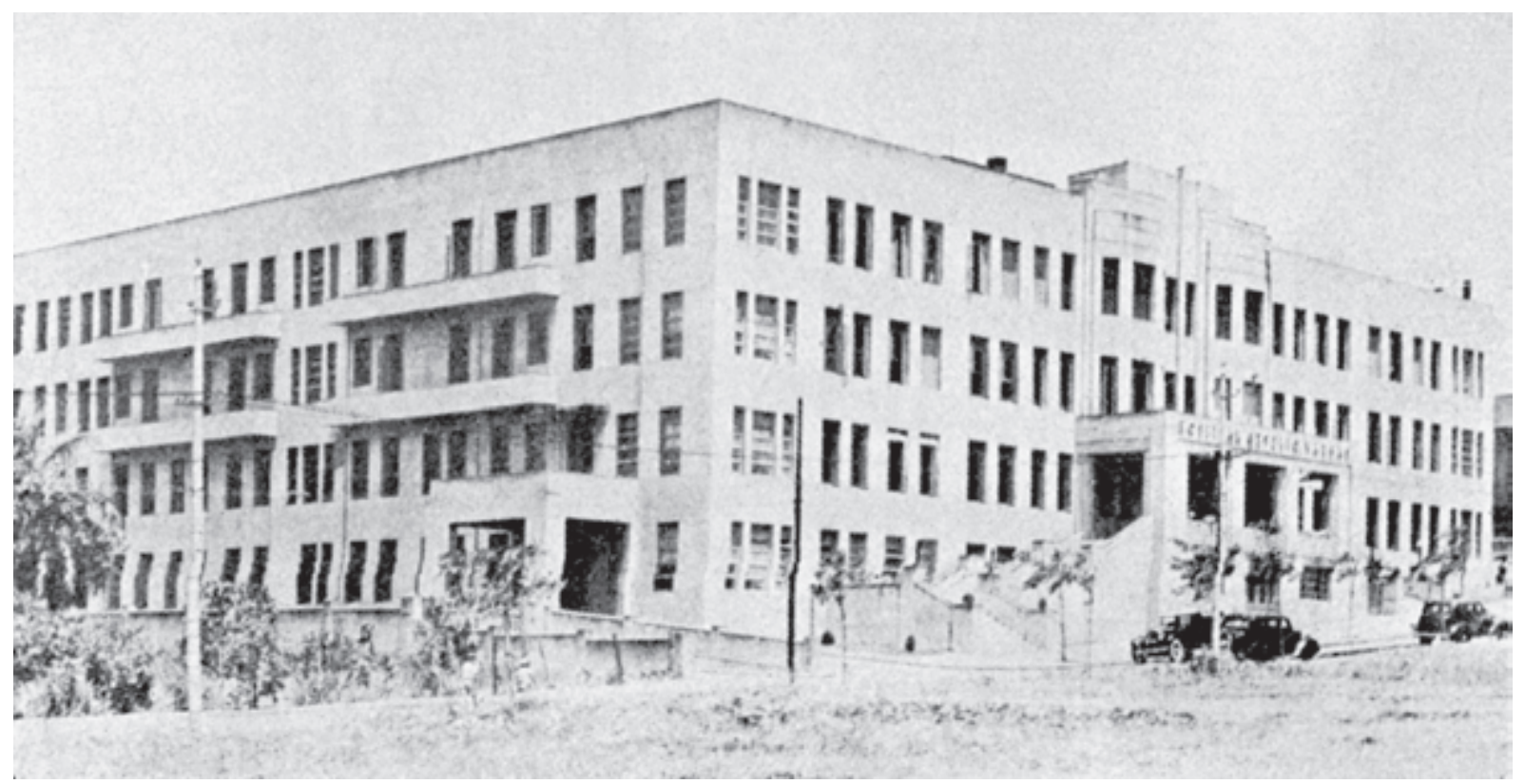

Hospital Getulio Vargas, [s.d.]. Fonte: Leonídio Ribeiro, 1956

Hospital Getulio Vargas em construção. Sua estética construtiva buscava uma aproximação com a linguagem do art déco norte-americano, uma alternativa aos padrões mais rigorosos do que seria mais tarde reconhecido como moderna arquitetura brasileira.

Hospital Santa Maria, [s.d.].

Acervo Cpdoc/FGV

Vista das varandas para tratamento da tuberculose óssea pela helioterapia, do Sanatório Santa Maria.

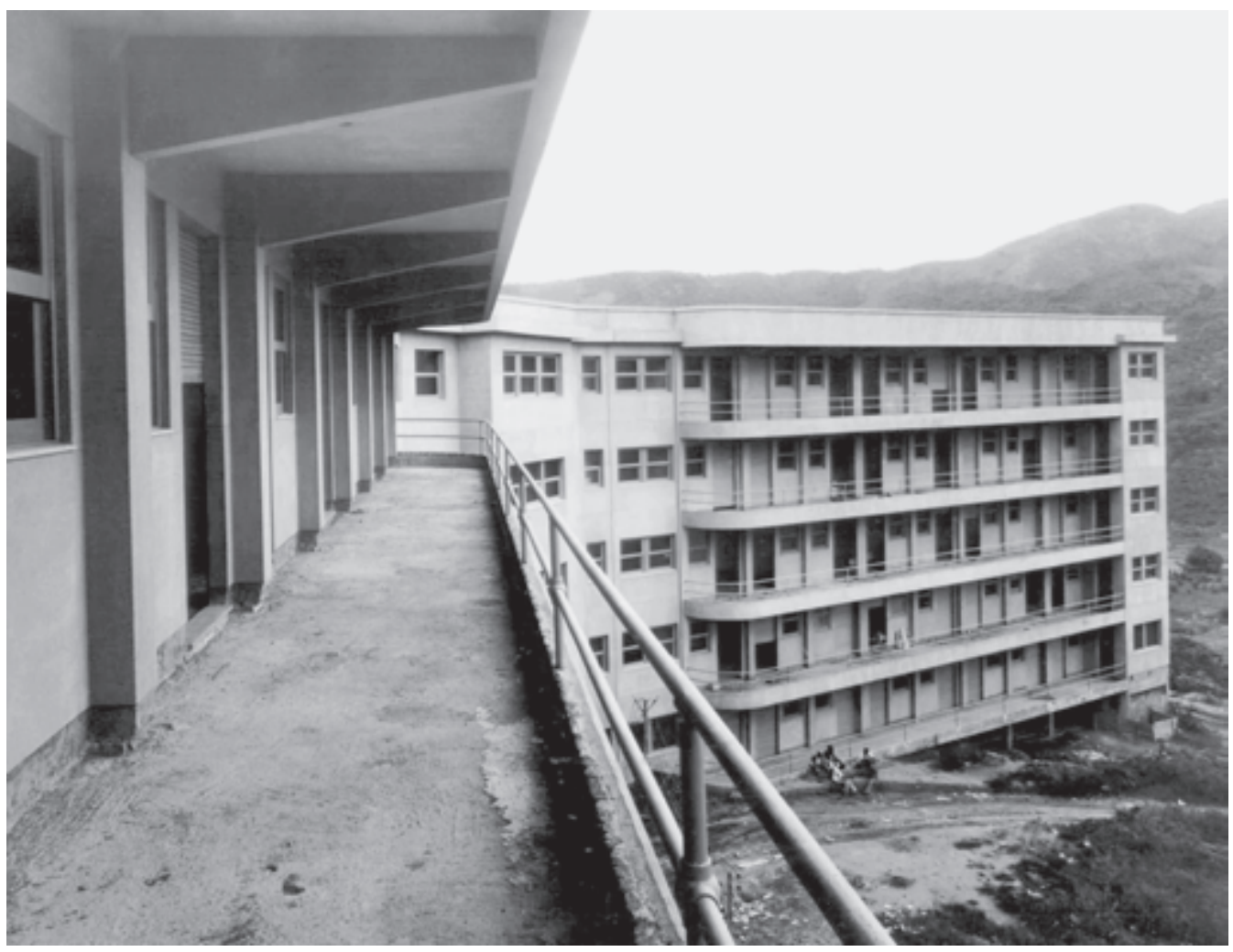




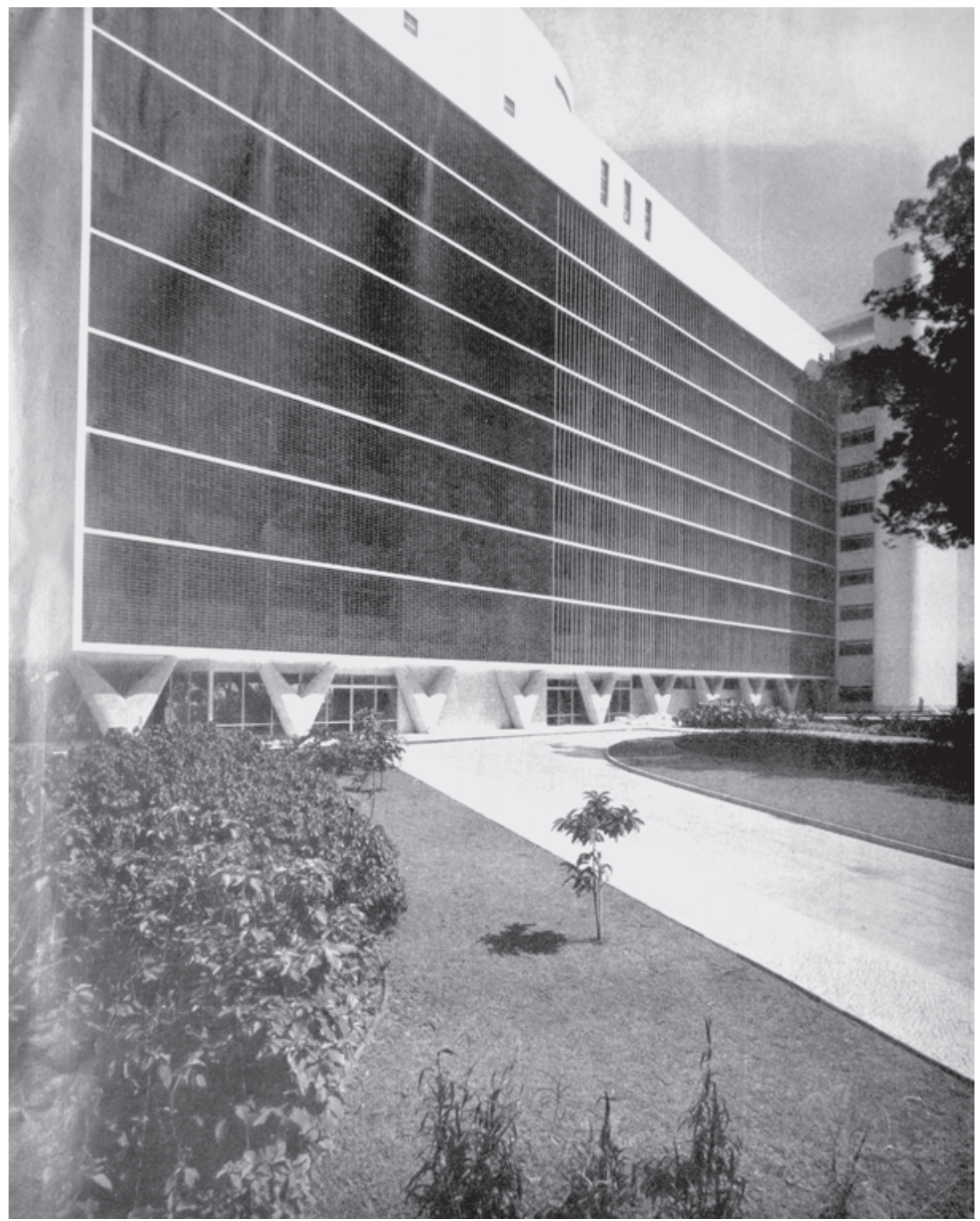

Hospital da Lagoa, [s.d.]. Fonte: Módulo, v. III, n. 14

Fachada do Hospital da Lagoa, projeto de Oscar Niemeyer e Hélio Uchoa, construído para a Companhia SulAmérica Seguros. 
